\title{
Children of Mothers Diagnosed With Serious Mental Illness: Patterns and Predictors of Service Use
}

\author{
Carol T. Mowbray, ${ }^{1,5}$ Lisa Lewandowski, ${ }^{1}$ Deborah Bybee, ${ }^{2}$ and Daphna Oyserman ${ }^{1,3,4}$
}

\begin{abstract}
Children who have a parent diagnosed with a mental illness are at risk of psychiatric and behavioral problems; yet, these children do not necessarily receive needed services. Research has investigated correlates of child mental health service use, but not for these high-risk children. This study is part of an NIMH-funded, longitudinal investigation and describes child problems, service use, and predictors of service use for 506 children of 252 mothers diagnosed with serious mental illness. Mothers are primarily poor, minority women from urban areas. A multilevel-model approach is used to examine service use for multiple siblings in a family. More than one third of children had received services (from school or mental health agencies) in their lifetimes. Service use was predicted by child demographic characteristics (being male, non-African American, and older), social context variables (more negative life events, less financial satisfaction, and more parenting dissatisfaction), and maternal psychiatric variables (positively by high levels of case management receipt and affective diagnoses, negatively by maternal substance abuse history). In a subsample of "target children," mothers' rating of child behavior problems additionally predicted service use. Implications of results for research and intervention are discussed.
\end{abstract}

KEY WORDS: children; service utilization; serious mental illness; high-risk youth; minority groups; motherhood.

Children of parents diagnosed with mental illness are at greater risk of having problemsincluding psychiatric disorders (Lapalme, Hodgins, \& LaRoche, 1997; Nomura, Wickramaratne, Warner, Mufson, \& Weissman, 2002), interpersonal difficulties, and behavioral problems (Larsson, KnutssonMedin, Sundelin, \& Trost von Werder, 2000)—-than children of nondiagnosed parents. Yet few children

\footnotetext{
${ }^{1}$ School of Social Work, University of Michigan, Ann Arbor, Michigan.

${ }^{2}$ Department of Psychology, Michigan State University, East Lansing, Michigan.

${ }^{3}$ Department of Psychology, University of Michigan, Ann Arbor, Michigan.

${ }^{4}$ Institute for Social Research, University of Michigan, Ann Arbor, Michigan.

${ }^{5}$ Correspondence should be directed to Carol T. Mowbray, School of Social Work, University of Michigan, 1080 South University Avenue, Ann Arbor, Michigan, 48109-1106; e-mail: cmowbray@umich.edu.
}

who have a parent diagnosed with a mental illness receive services (Tamarit \& Lau, 1999), perhaps because the mother's mental health care provider has neglected to find out if she is a parent, and, therefore, does not know whether or not her children have service needs (Sands, 1995; Zemencuk, Rogosch, \& Mowbray, 1995). There is also evidence that services to children are provided on the basis of issues other than the child's need (Saunders, Resnick, Hoberman, \& Blum, 1994; Striley, Stiffman, \& Spitznagel, 2003). Furthermore, it has been estimated that in a 12 -month period, 1.0 to $7.5 \%$ of children receive mental-health or mental-health-related services; yet, approximately $20 \%$ of children meet diagnostic criteria for a mental disorder, and $79 \%$ of children with a need for mental health services do not actually receive them (Costello et al., 1996; Costello, Burns, Angold, \& Leaf, 1993; Kataoka, Zhang, \& Wells, 2002).

In this paper, we first review the literature on factors related to service use of children in the 
general population. Then, we describe service use in a sample of children whose mothers receive public mental health services, and examine factors that predict service receipt, selected from the prior literature review.

\section{Predictors of Child Service Use}

Although there are a large number of studies on child/adolescent use of services to address mental health/behavioral problems, their diversity makes comparisons and conclusions difficult. Studies are population-based, or involve subsets of the population with a diagnosed disorder or specified behavioral problems, or are limited to families seeking or referred for treatment. Because the purpose of this review is to identify variables relevant to the proposed analyses, we have confined ourselves to populationbased samples, published in the last 6 years. In most of these studies, parents are asked whether their children have received any services which are intended to address mental health, emotional, or behavioral problems-received from a professional (psychiatrist, psychologist, social worker) or from a mental health, school, or medical setting. Even so, there are still methodological differences among these studies, in terms of the ages of children studied, the definition of services used (e.g., whether substance abuse services or school-based services are or are not included), the survey respondents, and the time frames covered. To inform readers, the studies selected are summarized in Table 1 . The major variables that have been examined are demographics (age, gender, race/ethnicity), income and insurance status, child level of need or disturbance, family characteristics, and diverse contextual factors. Table footnotes provide information on how "service use" was defined in each study.

\section{Demographic Variables}

Concerning age as a factor, more studies find that older children/adolescents are-on the basis of a simple count of significant results-more likely to receive services than younger children. Of course, this would be expected for studies of lifetime use. However, even when confined to the past year, many studies report significant age differences favoring older children. In terms of gender differences, a majority of studies find that males are significantly more likely than females to receive mental-health-related services; although several studies found no differences and one reported girls receiving more lifetime services than boys. Race/ethnicity findings are quite consistent, with White populations typically receiving significantly more services than Black or Hispanic populations (when they are studied) —although some studies did report no differences.

We expect our results to be consistent with the majority of these population-based research studies: that male children will be more likely to receive services than female, that children who are older will be more likely to receive services than those who are younger, and that African American children will be less likely to receive services when compared to White children.

\section{Income and Insurance Status}

Few studies have examined the effects of income on service receipt, and results are inconsistent. Studies have reported that child/adolescent service receipt is more likely both in poverty and in highincome populations; there were no significant differences as well. Insurance status seems to be a more meaningful predictor. Cohen and Hesselbart (1993) suggest that the relationship between SES and service use may be curvilinear: children from poor or wealthy families being more likely than those from the middle class to have contacts or resources needed to get services. The existence of a curvilinear relationship would help to explain some inconsistencies, as well as possibly why some studies find no relationship between SES and service use. Also, the absence of a relationship between SES and service may be due to increased availability of services in the locations where studies were conducted or may be a result of the restricted ranges of SES in samples. Interpreting research findings is further complicated by the fact that SES is often confounded with race. Inconsistent results from research investigating the relationship between child service use and material resources make it difficult to predict what relationships we might find in the current sample. Consequently, we included a measure of SES in our analysis for exploratory purposes.

In examining the effect of insurance coverage, with one exception, all the studies that included this variable found that children with public insurance (i.e., Medicaid) are more likely to receive services than uninsured or privately insured families or both. 


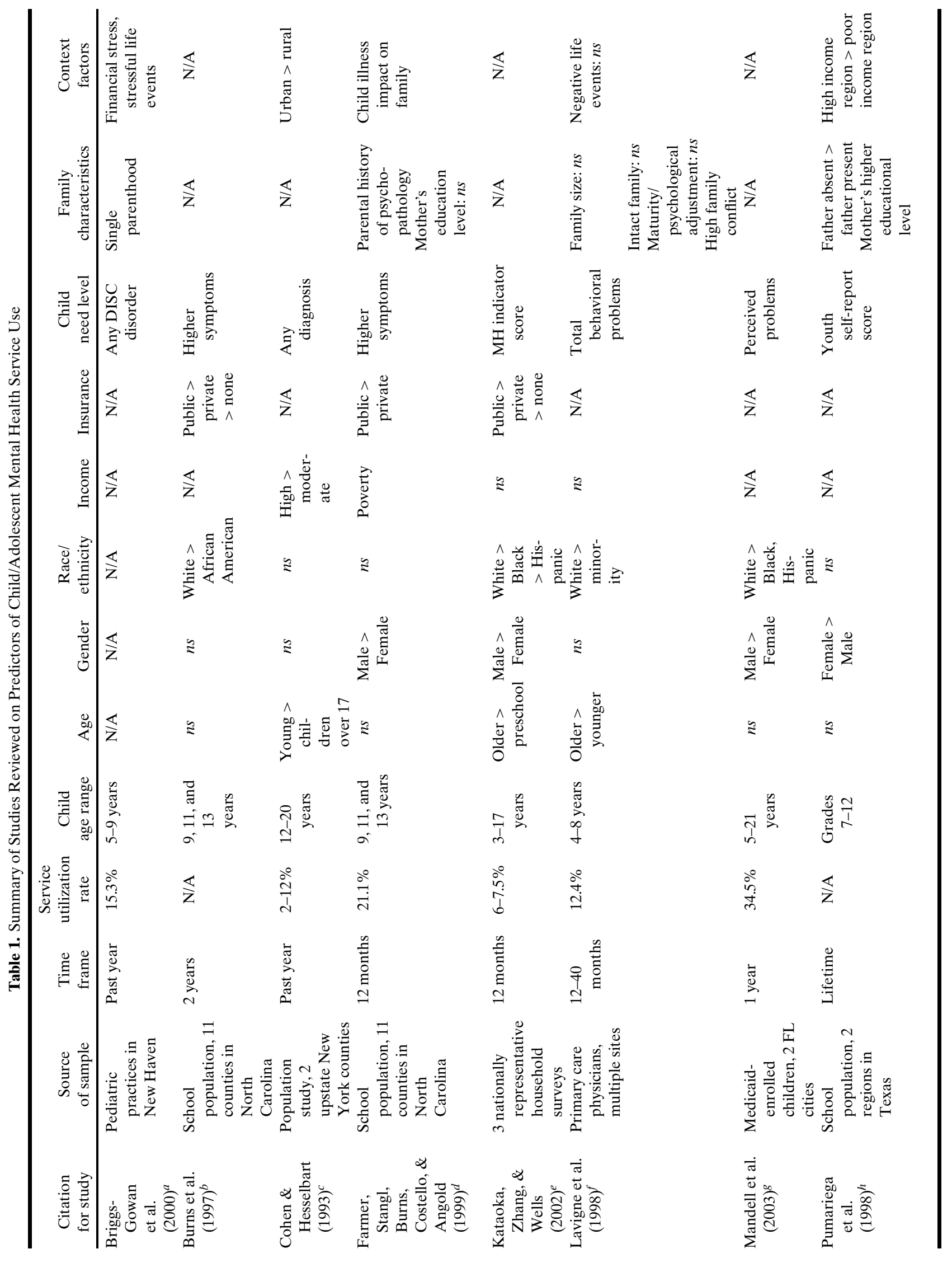




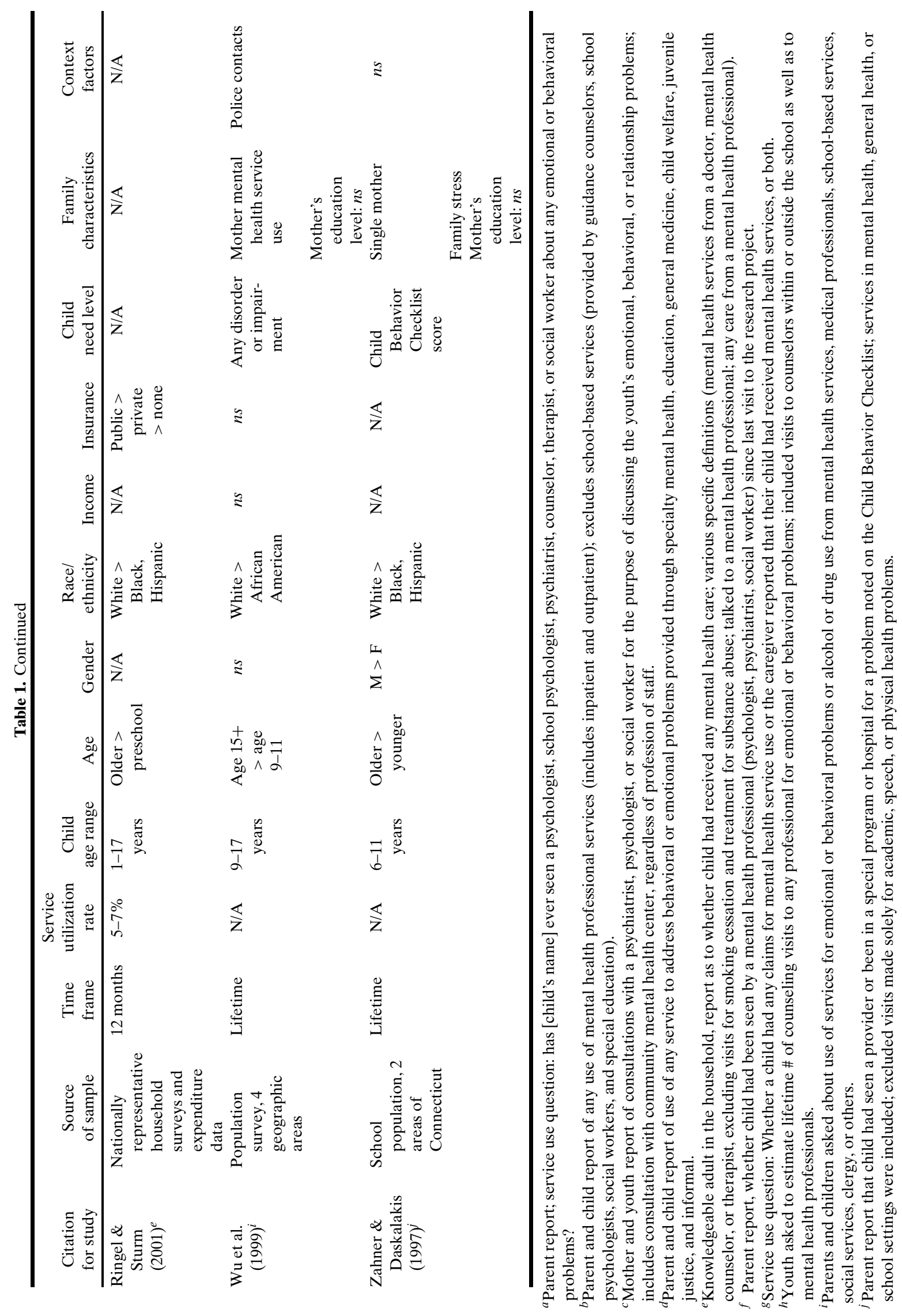


The one exception (Wu et al., 1999) combined those with private and public insurance into one group and compared them to the uninsured-which may explain the lack of relationship. Consequently, we hypothesized that in our sample, mothers on Aid to Families with Dependent Children (AFDC, now Temporary Assistance to Needy Families, TANF), Social Security Income (SSI) or Social Security Disability Income (SSDI) - programs that provide public insurance for children-are more likely than those without to have a child in services.

\section{Children's Level of Need}

Most general population studies have included some measure of child mental health/behavioral problems or parents' perceived level of need. The studies reviewed were consistent in finding that children with a diagnosed disorder, higher symptom levels, more behavioral problems, or higher need perceived by parents were more likely to be receiving services. However, these findings are sometimes questioned as to the cause and effect relationship. That is, does a child receiving services reflect parents' identification of problems and needs, or does the child being referred to or seen in services affect parental perceptions? Such attribution issues are even more problematic when parents have a diagnosable psychiatric disorder, particularly depression (Boyle \& Pickles, 1997). In the present study, data on child level of need was only available for one child per family, based on maternal rating of child behavior problems.

\section{Family Characteristics and Contextual Factors}

Most studies that examined a family characteristic variable did find that it had a significant effect on mental health service use. However, the characteristics studied varied widely. They include single parenthood (two studies), maternal mental health service use, parental history of psychopathology, parental higher education, more family stress, and father absent (vs. father present) - all of which predicted a greater likelihood of service receipt. The context variables examined were also diverse. Studies reported greater likelihood of child service use to be related to urbanicity, resource levels of the geographic area, and police contacts. In this study, we were able to examine the following family character- istics and contextual variables for effects on child service use: maternal education, psychiatric history and service use, and family stressors (e.g., financial, negative life events, parenting relationships).

In summary, prior research results suggest that child service use is associated with child, family, and social context characteristics, but with some inconsistencies. For the most part, studies have not focused on examining correlates of service receipt by children who have mothers being treated for serious mental illness. Given the at-risk status of these children, this is a significant issue.

The purpose of this study is to describe service use and its predictors, using a multilevel-model approach that includes multiple siblings in a family, for a sample of children whose mothers have a serious mental illness. This approach allows identification of the predictive value of both shared and unique characteristics of children within the same family. This is important, given that variability within families has not been addressed by other studies (Briggs-Gowan, Horwitz, Schwab-Stone, Leventhal, \& Leaf, 2000; Cuffe et al., 2001; Weissman, Warner, Wickramaratne, Moreau, \& Olfson, 1997). The mothers in our study are primarily minority women from low-income, urban areas. All were in treatment at the time of recruitment and met diagnostic criteria for a serious mental illness (mean age of onset was 26 years of age and mean duration of illness, 13 years). We examined the extent to which these mothers' children were receiving services. We hypothesized that as in the general population, receiving services would be predicted by child characteristics (being male, non-African American, and older), insurance status, family characteristics (high maternal education, single parenting, maternal psychiatric history), and social context (negative life events, parent-child relationship, financial stress). In addition, we included a measure of poverty to explore its predictive value in this sample and, in post hoc analyses, examined the extent to which the predictors differed when child level of need was taken into account.

\section{METHODS}

\section{Participants}

Participants were from a longitudinal, NIMHfunded study of mothers with serious mental illness. They were recruited from 12 community mental 
health centers and from the inpatient psychiatric units of three hospitals in southeastern Michigan. To be eligible, women had to be between 18 and 55 years of age, have primary care responsibilities for at least one child ages 4 to 16 , and have a diagnosis of mental illness, persisting for at least 1 year and causing functional limitations.

Interviews were conducted in three waves over the course of 5 years. Of the 485 women identified as eligible through their mental health provider, 379 were interviewed at the first wave of data collection (46 could not be contacted or scheduled, 59 refused to be involved, and 1 died between time of recruitment and the interview). Attrition over the course of the study was less than $13 \%$ (excluding women who died) and resulted in 322 mothers interviewed at Wave 3. Child service questions were included in Wave 3 data collection. Nonbiological children and those who were separated from their mothers at Wave 3 and who had been separated for over half of their lives were excluded from the present analysis to eliminate potential reporting errors resulting from lack of contact; 252 mothers from the Wave 3 sample with biological children under the age of 18 met our inclusion criteria. A total of 506 children were available for the current analysis.

\section{Description of Mothers and Children}

The median age of mothers was 39 years when service data were collected (Wave 3). Mothers' median number of children was 3. Slightly over half of the mothers were African American, about a third were non-Hispanic White, less than $10 \%$ were Hispanic or of other race/ethnicity. Median monthly family income was $\$ 1,200$. According to DIS-generated maternal diagnoses, the most prevalent was major depression, followed by mixed psychotic/affective diagnoses; only about $20 \%$ of the total sample were diagnosed with either schizophrenia or bipolar disorder. For 21 women $(8.3 \%$ of the total), no research diagnosis could be made. The median age of the children was 11 years; slightly more than half were male (See Table 2).

\section{Interviews}

Interviewers were all women, with at least an undergraduate degree in a human service field. They were trained and supervised by a master's level interview coordinator, who assured interview quality by

Table 2. Descriptive Information for Mothers $(n=252)$ and

\section{Children $(n=506)$}

\begin{tabular}{lrr}
\hline \multicolumn{1}{c}{ Variable } & \multicolumn{1}{c}{$M d n$} & $\%$ \\
\hline Monthly family income & $\$ 1,200.00$ & - \\
No. of children per family & 3.00 & - \\
Mother's age (years) & 39.00 & - \\
Child's age (years) & 11.00 & - \\
Child's sex & - & 55.1 \\
Male & - & 44.9 \\
Female & - & \\
Mother's race & - & 31.70 \\
$\quad$ African American & - & 7.50 \\
Non-Hispanic White & - & 2.80 \\
Hispanic & & \\
Other & - & 9.10 \\
Maternal psychiatric diagnosis & - & 38.90 \\
Schizophrenia & - & 11.10 \\
Major depression & - & 32.50 \\
Bipolar disorder & & 8.30 \\
Mixed psychotic/affective & & \\
Missing & &
\end{tabular}

reviewing audiotapes and checking completed forms. Interviews lasted about 2 hours and were conducted in participants' homes. Women were compensated $\$ 15$ for each of the two Wave 1 sessions, $\$ 30$ for the Wave 2 interview, and $\$ 40$ for Wave 3.

In all three waves, the interview covered the domains of child characteristics (e.g., race), mothers' psychiatric background, family characteristics, and social context. Most questions covered all of the mothers' children, except that some child-specific measures were asked about a target child (the youngest school-age child in each family). Information was gathered about service use of each minor child in Wave 3.

\section{Measures}

Unless otherwise noted, measures of predictors were taken from Wave 2 because they were believed to best reflect average family functioning (e.g., measures at this time period were less likely than those at Wave 1 to reflect selection criteria [mothers in treatment] or to be affected by concurrent [Wave 3] reports of child service use). The time interval between each wave was about 20 months, on average.

\section{Child Characteristics}

Child demographics at Wave 3 included age, race, and gender. 


\section{Family Characteristics}

Data included highest year of maternal education, marital status, household income as a percent of the federal poverty level, and whether or not mother was a recipient of SSI, SSDI, or AFDC/ TANF.

\section{Maternal Psychiatric Characteristics}

Substance abuse history was assessed only at Wave 1, using Skinner's (1982) Drug Abuse Screening Test (DAST) $(M=5.2 ; S D=4.8 ; \alpha=.94)$. Psychiatric diagnoses were also determined at Wave 1 using the Diagnostic Interview Schedule (Robins, Helzer, Croughan, \& Ratcliff, 1981), version III$\mathrm{R}$, modified for $D S M-I V$ criteria using the depression, mania, and psychosis modules. Interviewers were trained by a Ph.D.-level diagnostic consultant to assure accuracy. Finally, maternal involvement in mental health services was measured using questions adapted from the Client Resource Use instrument (Calsyn, 1993) and the Access Evaluation Form (Rosenheck \& Lam, 1994). Level and intensity of involvement were indicated by four service categories (no formal services, doctor/nurse only-no case management; once a month or less-low case management; and more than once per month-high case management).

\section{Social Context Variables}

From the Brief Life Events Questionnaire, 16 negative life event items were used (Brugha \& Cragg, 1990). Satisfaction with relationship with children was measured using an eight-item, 5-point Likert scale, selected from the Parenting Sense of Competence measure (Gibaud-Wallston \& Wandersman, 1978; $M=4.0 ; S D=0.8 ; \alpha=.84)$. Finally, the financial satisfaction scale was composed of three questions (Mowbray et al., 1999; $M=2.9 ; S D=1.04$; $\alpha=.79)$ : One asked mothers about their satisfaction with the family's financial situation on a 5-point scale $(1=$ completely satisfied through $5=$ not at all satisfied). The second asked mothers how difficult it is to pay monthly bills on a 5-point scale $(1=$ extremely difficult through $5=$ not at all difficult), and the third item used a 3-point scale asking mothers how finances looked at the end of the month $(1=$ some left over, 2 = just enough, 3 = not enough).

\section{Child Problems and Services}

To minimize the potential bias of relying solely on mothers' reports of child behaviors, we primarily asked participants to report what "others" (professionals, schools) had told them about their children's difficulties. Mothers were asked the following openended questions about each minor child at Wave 3:

- Has anyone from school ever told you that (child's name) has a special need or problem like learning disabled (LD)? If so, what were you told?

- Has (child's name) ever been given a mental health diagnosis? If yes, what were you told?

- All and all, other than what you just told me, would you say (child's name) has a disability or medical condition? What would you say it is?

- Has anyone ever told you that (child's name) has a drug or alcohol problem? What were you told?

Responses to these questions were coded into content categories on the basis of the consensus of research team members. Service use was based on combined answers from mothers to the following questions on each of their minor children:

- Has (child's name) ever received special services or resources at school? If yes, is (child's name) receiving these services now or has he/she in the past 12 months?

- Has (child's name) ever received mental health services? If yes, is (child's name) receiving these services now or has he/she in the past 12 months?

There is some support for mothers' being able to reliably report services received by their children (Canino et al., 2002). Child mental health and school service items were combined into a dummy variable for service use as an outcome measure in the multilevel modeling analyses. We combined these categories because in this geographic area, community mental health centers often have personnel located on site, in school buildings, accessed by teacher or school staff referrals or pupil/parent requests. Thus, we felt it would be difficult for mothers to accurately distinguish school from mental health services. This approach is consistent with that taken by other researchers who note that there is a large volume of mental-health-related services delivered in school settings and that using a broader service 
definition decreases stigma and enhances reporting (Pumariega, Glover, Holzer, \& Nguyen, 1998).

\section{Child Behavior Checklist}

Mother-reported child behavior problems, as measured by the Child Behavior Checklist (CBCL) (Achenbach, Howell, Quay, \& Conners, 1991; $\alpha=$ .75-.88), were obtained for a "target" child in each family $(N=252)$ - the youngest child over 4 ; by the third interview, all were more than 7 years of age.

\section{Analysis Plan}

As an initial step, basic descriptive statistics of child problems and service receipt were generated. Analyses of predictors of service use (excepting child level of need) were conducted using multilevel modeling with MIXOR software (Hedeker \& Gibbons, 1996), which performs random effects logistic regression analyses, appropriate for dichotomous outcomes of units nested within groups (e.g., children nested within families). This multilevel modeling approach is useful for analyzing nested data, because outcomes are modeled in terms of both individual (e.g., child) and group level variables (e.g., family). Estimates take into account the fact that outcomes for children within families are not independent and that multiple children in the same family share the same familylevel characteristics (e.g., the same maternal diagnosis), as well as different individual-level characteristics (e.g., child gender). With 506 children from 252 families, power was adequate to test the contribution of effects at both child and family levels.

Preliminary analyses were performed to explore bivariate relationships between service use and the hypothesized predictors, as follows. First, child demographic variables were modeled as predictors of child service use, one at a time. Child age, sex, and race were all significantly related to child service use. Service use increased across the range of children's ages; however, inspection of the scatterplot with a Lowess smooth (a nonparametric procedure that reflects departures from linearity [Cleveland, 1993] and can be used with a dichotomous dependent variable [Friendly, 2001]) indicated that this relationship was not as strong for children more than 10 years of age as for children age 10 and younger. To fully control for the potentially confounding effect of age, we characterized age as a linear piecewise function involv- ing two variables-an ordinary age variable reflecting the age of each child in the sample and an attenuation variable reflecting age for children older than 10 and taking on a value of zero for those 10 and under. The first variable expressed the strongly positive effect of age for younger children, and the combined effect of both variables expressed the weaker, but still positive, effect of age for older children. (See Raudenbush \& Bryk, 2002, for more detail about linear piecewise modeling.)

Second, controlling for child age, sex, and race, variables hypothesized to predict child service use were entered alone as predictors, as follows: family characteristics (maternal education, poverty, marital status, family receipt of AFDC/TANF or SSI/SSDI), maternal psychiatric history (diagnosis, level of service use, substance abuse history), and social context variables (negative life events, satisfaction with relationship with children, financial satisfaction).

Multilevel modeling was conducted in a hierarchical fashion. Predictor variables were entered in ordered blocks. Child demographic variables were entered first and served largely as controls. The second block contained family characteristics (such as mother's education). Block 3 consisted of maternal diagnosis, treatment level, and substance abuse history, so that the variability associated with maternal psychiatric history could be captured. Finally, after accounting for the variance associated with the first three blocks, block 4 was entered to reflect the contribution of context variables (e.g., negative life events, parenting satisfaction). At each successive block, variables that did not make at least a trend-level contribution to the model were removed, and the model was reestimated, in order to increase model stability and clarify interpretation of coefficients (Hedeker \& Gibbons, 1996; Hosmer \& Lemeshow, 2000).

To understand individual variation in service use within families, with the exception of analyses incorporating child need level, we included multiple siblings from the same family and used a multilevelmodel approach to appropriately analyze nonindependent cases. In the MLM analyses reported, the dependent variable is child service use, ever (lifetime). Results for lifetime versus past-year service use were essentially the same, as the two variables correlated at $0.75(p<.00)$. We selected lifetime use as we felt it was more valid, owing to several reasons: First, mothers had been originally enrolled in the study over about a 9-month period. Thus, followup data collection also occurred over the same time 
frame. Using mothers' reports of child service use in the past 12 months would create differences in the time periods covered; that is, the extent to which summer was (or was not) included. This might artificially lower or increase services received and reported by some mothers. Also, because of telescoping, we felt that mothers' recollection and report of services ever received by a child would be more accurate than limiting the time period to the past 12 months. For adults' reports of their own psychiatric service use, research indicates that reports are quite accurate in terms of overall receipt of services, but much less accurate in terms of time frames or amounts (Goldberg, Seybolt, \& Lehman, 2002).

To examine the effect of child need level on the predictors identified from the MLM analyses described above, a different analysis plan was utilized. Data on child need level was available only for one "target" child in each family, based on CBCL internalizing and externalizing ratings from mothers. We conducted two hierarchical logistic regressions, inserting CBCL internalizing or externalizing score as the second block, following child demographic variables. In the third and fourth blocks, we used the maternal psychiatric and social context variables found to be significant in the MLM analyses. For the two logistic regressions, CBCL scores were from Wave 2 . The dependent variable used in these two regressions was child service use in the last 12 months from Wave 3, to ensure that maternal CBCL ratings were predicting subsequent service use.

\section{RESULTS}

Descriptive demographic data for mothers and their children are provided in Table 2. Table 3 shows data on service receipt. Mental health services and school services had been received by over one third $(38.3 \%)$ of the children at some time in their lives. This lifetime rate was higher than rate of service use in the past 12 months; however, the latter was still high, with a quarter $(24.9 \%)$ of the children receiving at least one school or mental health service in the past year.

In terms of mothers being told their children had problems, mothers indicated that for more than a quarter of the children, they were told of a school problem (a special need or learning disability); about one sixth of children were identified as having a mental health problem; but few had a reported drug or alcohol problem, or both. Seventy-four percent of
Table 3. Percentage and Frequency of Mothers' Responses to Questions About Children's Problems $(N=506$ Children From 252 Families)

\begin{tabular}{|c|c|}
\hline Response & $\%$ (Frequency) \\
\hline $\begin{array}{l}\text { Never told that child had a school, mental } \\
\text { health, or substance abuse problem }\end{array}$ & $64.3(317)$ \\
\hline $\begin{array}{l}\text { Ever told that child had a school or } \\
\text { mental health problem }{ }^{a}\end{array}$ & $38.3(194)$ \\
\hline $\begin{array}{l}\text { Ever told that child had a substance } \\
\text { abuse problem }\end{array}$ & $3.0(15)$ \\
\hline $\begin{array}{l}\text { Child problems listed in open-ended } \\
\text { items }(N=140 \text { mothers responded })^{a}\end{array}$ & $16.4(83)$ \\
\hline $\begin{array}{l}\text { Cognitive problems (impaired academic } \\
\text { achievement or ability, or both) }\end{array}$ & $14.4(73)$ \\
\hline $\begin{array}{l}\text { Attention deficits and behavioral } \\
\text { disturbances (e.g., ADHD) }\end{array}$ & $7.9(40)$ \\
\hline $\begin{array}{l}\text { Mental disorder (e.g., depression, } \\
\text { psychosis) }\end{array}$ & \\
\hline $\begin{array}{l}\text { Developmental disability (including } \\
\text { autism) }\end{array}$ & $2.4(12)$ \\
\hline Drug/alcohol & $2.4(12)$ \\
\hline $\begin{array}{l}\text { Neurological/sensory/perceptual (e.g., } \\
\text { epilepsy) }\end{array}$ & $1.2(6)$ \\
\hline Other problem $^{b}$ & $1.4(7)$ \\
\hline
\end{tabular}

mothers who said they had been told that a child had a problem provided a response to the openended item asking what they were told; their answers were categorized and are listed in Table 3. The most common problem mothers reported being told involved impaired academic achievement or ability, or both. This was followed by ADHD/behavioral disturbances, and then mental disorders, such as depression or psychosis.

Table 4 lists the results of the bivariate multilevel analyses that identified potential predictors of child service use-ever for utilization in multilevel modeling. Child demographic variables (sex, race, and age) predicted significantly greater likelihood of service among older children and boys, and reduced likelihood of service use among African American children. The following variables were also significantly related to child service use-ever and thus were selected for inclusion in the full model: maternal psychiatric diagnosis, maternal involvement in mental health treatment, negative life events, financial satisfaction, and parenting satisfaction. Children whose mothers were diagnosed with schizophrenia were less likely to have received services than children whose mothers were diagnosed with schizoaffective, bipolar 
Table 4. Bivariate Multilevel Logistic Regression Analyses: Predictors of Lifetime Child Service Use $(N=506$ Children From 252 families)

\begin{tabular}{lrc}
\hline \multicolumn{1}{c}{ Predictor } & \multicolumn{1}{c}{$B$} & $p$ \\
\hline Child demographics & & \\
Sex (Male =1) & 0.84 & 0.00 \\
Race (African American =1) & -1.16 & 0.00 \\
Age (children ages 10 and under) & 0.43 & 0.00 \\
Age (attenuated effect among children & -0.40 & 0.01 \\
$\quad$ ages more than 10) & & \\
Family characteristics ${ }^{a}$ & & \\
Maternal education & -0.02 & 0.74 \\
Marital status (married as comparison) & & \\
$\quad$ Separated/divorced/widowed & 0.13 & 0.78 \\
$\quad$ Single & -0.07 & 0.88 \\
Income level (at or above poverty line & -0.42 & 0.26 \\
Receiving TANF/AFDC or SSI/SSDI & 0.24 & 0.59 \\
$\quad$ Yes = 1) & & \\
Maternal psychiatric history & \\
Diagnosis of schizophrenia & & \\
Substance abuse & -1.75 & 0.03 \\
Treatment (high case management & -0.03 & 0.38 \\
$\quad$ in comparison) & & \\
$\quad$ No formal services & & \\
$\quad$ Doctor/nurse only & -1.29 & 0.01 \\
$\quad$ Low case management & -0.89 & 0.09 \\
Social Context & \\
Negative life events & -1.38 & 0.01 \\
Parenting satisfaction & & \\
Financial satisfaction & 0.17 & 0.00 \\
\hline Childage, sex, and race were used as controls & -0.72 & 0.00 \\
& -0.42 & 0.01 \\
\hline
\end{tabular}

${ }^{a}$ Child age, sex, and race were used as controls.

(with and without psychosis), or major depression (with and without psychosis) disorders. Schizophrenia was, therefore, used as the comparison category in the multilevel modeling analysis, and the remaining diagnostic categories were collapsed. Children of mothers who received higher levels of case management were more likely to have received services than those receiving no services, doctor/nurse services only (trend level), or low levels of case management services. In terms of social context variables, high levels of negative life events predicted child service receipt, as did low levels of parenting and financial satisfaction.

The final combined model to predict children's lifetime use of mental health or school services, or both, included variables from each of the three blocks of predictors: child demographics, maternal psychiatric history, and social context (see Table 5). In addition to variables that were significant bivariate predictors of service use, substance abuse was also included in the combined model because of the importance of this variable in the literature, e.g., the high percentage of adults
Table 5. Multilevel Logistic Regression Analysis: Final Combined Model Predicting Lifetime Child Service Use $(N=506$ Children from 252 Families)

\begin{tabular}{lrc}
\multicolumn{1}{c}{ Predictor } & \multicolumn{1}{c}{$B$} & $p$ \\
\hline Child demographics & & \\
Sex (Male = 1) & 0.78 & 0.01 \\
Race (African American =1) & -1.15 & 0.00 \\
Age (children ages 10 and under) & 0.38 & 0.00 \\
Age (attenuated effect among & -0.33 & 0.05 \\
children ages more than 10) & & \\
Maternal psychiatric history & -1.40 & 0.06 \\
$\quad$ Diagnosis of schizophrenia & -0.07 & 0.04 \\
Substance abuse & & \\
Treatment (high case management & & \\
$\quad$ as comparison) & -1.13 & 0.02 \\
$\quad$ No formal services & -0.57 & 0.28 \\
$\quad$ Doctor/nurse only & -1.07 & 0.04 \\
$\quad$ Low case management & & \\
Social context & 0.12 & 0.05 \\
$\quad$ Negative life events & -0.55 & 0.03 \\
$\quad$ Parenting satisfaction & -0.30 & 0.08 \\
$\quad$ Financial satisfaction & & \\
\hline
\end{tabular}

with mental illness who also have substance abuse problems.

None of the variables in the family characteristic block made a significant contribution, so this block was omitted from the final model. All variables in the child demographics block were significantly related to child service use. Male children were more likely than female children to have received services ever, as were Non-African American children when compared to African American children. In addition, older children were more likely than younger children to have received services ever; however, age was less strongly related to service receipt for children more than 10 years of age.

Maternal psychiatric history variables were significantly related (diagnosis at trend level) to child service use-ever. Children whose mothers had more extensive substance abuse histories were significantly less likely to have ever received services; and children of mothers with schizophrenia were less likely than children of mothers with other diagnoses to have received services. Children of mothers receiving high levels of case management were more likely to get services when compared to those not in services or receiving low levels of case management services.

Finally, variables from the social context block were also significantly related to child service use. Children whose mothers reported more negative life events were more likely to have received services, as were children whose mothers reported less 
satisfaction with their relationship with their children or with their financial situation.

To explore the possibility that males were more likely to receive services owing to externalizing behavior problems, a post hoc analysis was performed to investigate the relationship between externalizing (as reported by mothers on the CBCL) and child service use. A logistic regression was conducted for the subgroup of target children (biological and under the age of 18 years, $N=252$ ) for whom CBCL scores were available. Controlling for child age, race, and sex, a significant and positive relationship between externalization and receipt of child services was found $(B=0.06, p=.00)$, suggesting that their externalizing behaviors may have contributed to boys' being more likely to receive services. We went on to conduct further exploratory analyses to determine if externalizing behaviors served as a mediator between male sex and child service use. However, results failed to confirm the mediational hypothesis.

Table 6 provides information on the final set of analyses: predicting child service use in the past year, and including mother ratings on the $\mathrm{CBCL}$ from Wave 2, as well as maternal psychiatric and social contextual variables. As previously described, these analyses involved one child per family. Two separate logistic regressions were conducted, involving CBCL Externalizing and CBCL Internalizing scores.

In the final logistic regression model, CBCL Externalizing scores (from Wave 2) made a significant contribution to the prediction of past 12 months' child service use, above and beyond the effects of child demographics (sex, race, and age). However, even controlling for demographics and CBCL, maternal psychiatric variables (DAS count and high case management) were still significant predictors, as were social contextual variables (financial satisfaction). The same basic results were obtained when CBCL Internalizing scores were used in the logistic regression.

\section{DISCUSSION}

\section{Service Use-Descriptives}

The analyses revealed that $38.3 \%$ of the children had received at least one mental health or school service at some point in time and that $24.9 \%$ had received at least one of the two types of service in the past year. The latter rate is higher than those reported in national surveys for the general child
Table 6. Final Models for Logistic Regression Analysis Predicting Child Service Use in the Past 12 Months: CBCL (Internalizing and Externalizing Separately) as Block 2 Predictors $(N=252$ Target Children)

\begin{tabular}{|c|c|c|}
\hline Predictor & $B$ & $p$ \\
\hline \multicolumn{3}{|l|}{ Child demographics } \\
\hline Sex $($ Male = 1) & 0.51 & 0.19 \\
\hline Race (African American = 1) & -0.89 & 0.03 \\
\hline Age (children ages 10 and under) & 0.09 & 0.69 \\
\hline $\begin{array}{l}\text { Age (attenuated effect among } \\
\text { children ages more than 10) }\end{array}$ & -0.11 & 0.72 \\
\hline$C B C L$ Internalizing & 0.07 & 0.00 \\
\hline \multicolumn{3}{|l|}{ Maternal psychiatric history } \\
\hline Diagnosis of schizophrenia & -0.40 & 0.60 \\
\hline Substance abuse & -0.11 & 0.02 \\
\hline \multicolumn{3}{|c|}{ Treatment (high case management as comparison) } \\
\hline No formal services & -1.03 & 0.05 \\
\hline Doctor/nurse only & -0.88 & 0.12 \\
\hline Low case management & -0.90 & 0.08 \\
\hline \multicolumn{3}{|l|}{ Social context } \\
\hline Negative life events & 0.03 & 0.67 \\
\hline Parenting satisfaction & 0.16 & 0.57 \\
\hline Financial satisfaction & -0.52 & 0.01 \\
\hline \multicolumn{3}{|l|}{ Child demographics } \\
\hline $\operatorname{Sex}($ Male $=1)$ & 0.55 & 0.17 \\
\hline Race (African American =1) & -0.99 & 0.02 \\
\hline Age (children ages 10 and under) & 0.26 & 0.29 \\
\hline $\begin{array}{l}\text { Age (attenuated effect among } \\
\text { children ages more than 10) }\end{array}$ & -0.32 & 0.31 \\
\hline$C B C L$ Externalizing & 0.08 & 0.00 \\
\hline \multicolumn{3}{|l|}{ Maternal psychiatric history } \\
\hline Diagnosis of schizophrenia & -0.08 & 0.92 \\
\hline Substance abuse & -0.13 & 0.01 \\
\hline \multicolumn{3}{|c|}{ Treatment (high case management as comparison) } \\
\hline No formal services & -1.26 & 0.02 \\
\hline Doctor/nurse only & -1.18 & 0.04 \\
\hline Low case management & -1.06 & 0.04 \\
\hline \multicolumn{3}{|l|}{ Social Context } \\
\hline Negative life events & 0.05 & 0.51 \\
\hline Parenting satisfaction & 0.31 & 0.28 \\
\hline Financial satisfaction & -0.55 & 0.01 \\
\hline
\end{tabular}

population, where past-year mental health service use rates are in the range of 1 to $7.5 \%$ (Kataoka et al., 2002; Ringel \& Sturm, 2001). This would be expected, given the greater risk status of the children in our study, and the fact that our reported rates include school as well as mental health services.

The most common problems listed by mothers were quite typical of those identified and treated in school and child mental health systems, overall, and are congruent with the literature on children of parents with mental illness. That is, research has indicated that offspring of mothers with a mental disorder are more likely to have a diagnosis themselves (Lieb, Isensee, Hofler, Pfister, \& Wittchen, 2002), including childhood attention and conduct problems 
(Boyle \& Pickles, 1997; Fergusson \& Lynskey, 1993), which are likely to interfere with the ability to perform at school. Few children had drug/alcohol problems. This probably reflects the broad age range of children in this study, with a median age of 11 . Drug and alcohol problems are more likely to be detected in high-school-age adolescents.

\section{Predictors of Child Lifetime Service Use-Demographic Variables}

Our results indicate that White children are more likely than African American children to receive services, even controlling for other demographic factors. This is consistent with other studies (Burns et al., 1997; Lavigne et al., 1998; Mandell, Boothroyd, \& Stiles, 2003; Wu et al., 1999; Zahner \& Daskalakis, 1997), including national surveys (Kataoka et al., 2002; Ringel \& Sturm, 2001). An oft-proposed explanation for such findings is that minority youth are more likely to use informal networks when they need help, such as the church or family (Mcmiller \& Weisz, 1996). Other researchers have hypothesized that racial differences reflect minority populations' distrust of professionals (Cauce et al., 2002); this may be especially true in the present study, in which all the mothers have had extensive contact with mental health systems and often with other systems as well (child welfare, social services, Social Security).

We also found that older children are more likely than younger children to have received services, with a tapering off of this positive relationship after age 10 . The linear part of this result is consistent with other research. For instance, national surveys find that older versus younger children have higher mental health service use rates $(6-8 \%$ average yearly use for 6 - to 11 -year-olds and a $7-9 \%$ average yearly use for 12 - to 17 -year-olds, compared to only $1-2 \%$ average yearly use in preschoolers; Ringel \& Sturm, 2001). Age effects may be due to the fact that parents wait to get help because they want to see if children grow out of problems; or that problems are only recognized and treated when noticed by others or when children become disruptive, as in a school setting (Lavigne et al., 1998). With older age, there is also more time for problems to be detected and labeled and more time for problems to surface, as children face more risk factors.

The tapering off of the positive relationship after age 10 appears to be unique to this study; con- sequently, it may reflect characteristics of this sample. For example, it is possible that as these children of mothers with mental illness approach the teen years, they may be at greater risk of dropping out of school or engaging in other behavior that produces estrangement from agencies providing services (e.g., schools). Or it may be that the finding represents resilience-that is, children from this high-risk group who have not been identified as needing services by age 10 may constitute a "resilient" group that has the supports or individual characteristics to promote stability, thus avoiding services, although they continue to face risks. It may also be that the nonlinear aspect of this relationship has not been examined in previous research.

We also found that male children in the sample were more likely than females to have received services. Again, this is consistent with most research and probably reflects the types of problems commonly exhibited by males versus females. This conclusion was somewhat supported in the post hoc analysis, which found a significant relationship between current externalizing behavior and the use of services, even after controlling for race, sex, and age of the child, although externalizing behavior was not a significant mediator of the relationship between male sex and child service use. The lack of mediating relationship may reflect differences in time frames. However, internalizing versus externalizing behaviors, as an explanation for the relationship between gender and service use, cannot be fully supported in this study.

The analyses indicated that child service use did not relate to maternal background variablessingle marital status, adjusted income, or education. Prior research has shown a relationship between service use and single parenthood (Briggs-Gowan et al., 2000); however, just under a quarter of the mothers in this study were married. The rest were separated, widowed, divorced, or single/never married. The lower marriage rate in our sample may account for the lack of relationship. However, for women with a mental illness (compared to those in the general population), marriage seems to be less likely to provide supports, as women with mental illness are more often in troubled, conflictual marriages (Levkovitz, Fennig, Horesh, Barak, \& Treves, 2000; Mowbray et al., 2000; Ritsher, Coursey, \& Farrell, 1997) or have spouses with psychiatric disorders (Miller, 1997). Concerning the effect of maternal education and child service use, reported in one other study (Pumariega et al., 1998), there was 
no relationship in this study-perhaps because most women in our sample (about two thirds) have a high school education or more, restricting the number of women at the lower end of the education spectrum. Or, perhaps a relationship with education is nullified in the context of public mental health services, which are so limited that even higher education levels will not assist mothers in being able to access needed resources. Alternatively, the single significant relationship with education reported might be due to confounding effects of insurance availability or economic status, which the researchers had not assessed.

We also found no relationship between child service use and household income. This outcome is probably due to the narrow income range in this sample, wherein two thirds of mothers were below the poverty line. We also found no relationship with public insurance access (being on SSI/SSDI or AFDC/TANF, or both). This is probably understandable because both school and public mental health system service use was included in the outcome measure. Specialty services received via the education system are not likely to require the use of insurance (Ringel \& Sturm, 2001), nor are publicly funded $\mathrm{MH}$ services.

\section{Predictors of Service Use-Psychiatric and Context Variables}

The literature on the relationship between specific parental mental illness diagnoses and child outcomes is limited. Research typically focuses on the link between parental depression and child mental illness (Beardslee \& Wheelock, 1994; Boyle \& Pickles, 1997); children of parents with affective disorders have higher rates of diagnosed mental illnesses than children of non-mentally ill controls (Beardslee et al., 1993). However, studies have not systematically compared child outcomes for depression versus other diagnoses, even though other diagnoses are often considered more severe in terms of their impact on role functioning (Oyserman, Mowbray, Allen-Meares, \& Firminger, 2000). Thus, children of parents diagnosed with bipolar disorder or schizophrenia may be at even greater risk than children of parents diagnosed with depression (Goodman \& Brumley, 1990).

In this study, if having a mother with schizophrenia is regarded as a "need" variable, then the relationship between mothers' schizophrenia diagnosis versus all others is counterintuitive. That is, adults with schizophrenia are usually seen as the most disabled and having the greatest problems with functioning. However, in other research with this study sample, we have found that the mothers with schizophrenia have more positive outcomes (Mowbray, Oyserman, Bybee, \& MacFarlane, 2003). This finding may be due to selection bias: women with schizophrenia in this study may not be truly representative of others with this diagnosis, because, to be in our sample, women had to have care responsibilities for their children. Those women with schizophrenia who have more problems with their functioning may lose custody of their children at an early age, and therefore would not have been eligible for this study. Alternatively, it could be that because of the greater stigma associated with a schizophrenia diagnosis, and consequent increased fear of custody loss, these mothers and their extended families avoid formal service utilization for their children.

Substance abuse was a negative predictor of likelihood of children receiving service. The variable we employed reflected a history of use rather than presence/absence of a substance abuse diagnosis (Cornelius, Pringle, Jernigan, Kirisci, \& Clark, 2001) - the greater the degree of substance abuse history, the less likely a child has received services. This result may be because drug use interferes with mothers' ability or desire, or both, to get children services and may also relate to fear of custody loss, rather than maternal drug use reflecting a need for services. Similarly, in studies of adults receiving mental health services for themselves, substance abuse is usually a negative predictor (Kruse, Rohland, \& Wu, 2002; Rosenheck \& Lam, 1997; Stein, Andersen, Koegel, \& Gelberg, 2000).

The analysis of psychiatric variables also indicated that mothers' treatment level related to likelihood of the child receiving services; mothers with high case management levels are more likely to have children who received services when compared to mothers receiving no services or low casemanagement levels. This result seems consistent with findings from the literature that children who have mothers who are in treatment (Wu et al., 1999) are more likely to receive services themselves. Several interpretations are possible-one being that mothers who drop out of services or receive less intensive services are less in need, and therefore their children are less likely to have received services. Another interpretation is that mothers with low levels or no services are expressing a dislike or distrust of services and are therefore less likely to let their children 
receive services. Finally, it could be simply that mothers with high levels of service use have more ready access to services for their children.

Our analyses indicated a significant impact of social context-contextual variables were important even after controlling for demographics and maternal psychiatric history. The significant effects of negative life events and financial satisfaction are consistent with other reported results; more negative life events and less financial satisfaction probably reflect more stress in the lives of these mothers. Other studies reported that more stressful life events and family conflict relate to greater likelihood of child service use (Briggs-Gowan et al., 2000; Lavigne et al., 1998). We also found that higher levels of parenting satisfaction were related to decreased likelihood of child service use. This result could be interpreted to mean that the more the mother is satisfied as a parent, the less parenting stress she feels (and the less need for child services). Research in the child problem literature has found an association between quality of parenting in parents with Bipolar Disorder and offspring risk of psychopathology (DelBello \& Geller, 2001). However, we should also acknowledge that lower levels of parenting satisfaction could be the result of children being in service. Even though we tried to minimize this possibility by using prior (Wave 2) measures of satisfaction, it is still a possibility because the child service use variable covers the child's lifetime.

The analyses on the subset of children with maternal CBCL ratings confirmed most of the above findings. Even with CBCL (internalizing or externalizing) entered as a predictor variable in a previous block, mothers' past substance abuse history, treatment level, and financial satisfaction were still significant predictors. However, the social contextual variables of negative life events and parenting satisfaction were no longer significant. This probably reflects the fact that maternal CBCL ratings are often seen to reflect mothers' overall distress (Youngstrom, Izard, \& Ackerman, 1999).

\section{Limitations and Strengths}

The limitations of this study need to be acknowledged. First, mothers were recruited from the public mental health system, in a predominantly urban area. Findings may thus not generalize to other samples of seriously mentally ill mothers. Second, the findings are based on mother report and therefore may be subject to the recall bias of the mothers or their subjective interpretations. However, the questions did not ask for mothers' opinions, but rather solicited a rather straightforward, factual response as to whether the child had received any of several specific types of services, in order to minimize judgments and recall problems. Third, information on the types of problems children experienced are limited because of missing data (i.e., only about three fourths of mothers answered the open-ended question). However, compared to other data available on this highrisk group of children, this report provides more information than was previously available. Finally, our data did not include any objective assessment of the child's actual behavioral problems. Although mothers did complete CBCL ratings, these were only done on one child in the family. Furthermore, the time for the CBCL rating is not necessarily when children were brought in for mental health service use. Also, mothers with depression have been questioned as valid reporters of children's mental health and behavioral problems (Boyle \& Pickles, 1997). Thus, in this analysis, we cannot definitely state that service use rates have accounted for whether or not a child actually had a disorder.

We feel that the strengths of the present report outweigh the limitations. The report serves to highlight the factors that may put these high-risk children at even greater risk. Results may thus be helpful in designing intervention and preventative efforts, for example, to target children where mothers express financial problems within a context of poverty-rather than simply considering the family's adjusted income. Second, the multilevel model of statistical analysis enabled us to account for the nonindependent data appropriately, rather than using analytic methods that assume all data points are independent, underestimating effects, or randomly selecting only one child from a household, and not utilizing the data on multiple children from the same family. Third, the use of control variables (e.g., child age, sex, and race) enabled us to identify independent predictors and to disentangle effects previously reported that may have reflected a confounding with race (such as poverty level or insurance source).

\section{Implications for Future Research}

Many of the identified predictors of child service use in this sample are consistent with general 
population studies, such as child age, sex, and race, and therefore future studies should be large and diverse enough to provide such controls. Of greatest interest are factors unique to this high-risk sample, for example, psychiatric diagnosis, parenting satisfaction, and contextual variables that may be more amenable to intervention and change (e.g., financial stress, negative life events). In our study, although we found that such factors had significant effects, their meaning was elusive, subject to several possible interpretations. Thus, additional qualitative research is needed to assess the process whereby these high-risk children come to educational or mental health services. We need to find out from the mothers themselves, through semistructured and probative interviews, what it is that causes their children to be in services-is it sources external to the family (school, mental health workers), or other family members' support or lack of support for this activity? Are differences due to factors that encourage/facilitate mothers' accessing child mental health services or to those that lead mothers away from services, such as fear of custody loss, distrust of professionals, prior bad experiences with professional services, availability of support services in other sectors or in religious communities? Once the above questions are answered through qualitative data collection and interpretation, research that is theory based should aim for a comprehensive study of predictors of child service use in a high-risk sample, like the present one. The study should fully investigate the whats and whys of service use. It should also provide comprehensive data on need indicators, from children as well as family members, concerning child diagnosis, symptomatology, current functioning, and past experiences of traumatic events. Results from this study should be verified, but incorporating a gold standard of what children's service needs are.

\section{ACKNOWLEDGMENTS}

This research was funded in part through NIMH grant \#R01 MH 54321 to the University of Michigan, School of Social Work and \# R01 MH57495 to the University of Michigan, Institute for Social Research.

\section{REFERENCES}

Achenbach, T. M., Howell, C. T., Quay, H. C., \& Conners, C. K. (1991). National survey of problems and competencies among 4 to 16 year-olds: Parents reports for normative and clinical samples. Monographs of the Society for Research in Child Development, 56(3), R5-R119.

Beardslee, W. R., Salt, P., Porterfield, K., Rothberg, P. C., Van de Velde, P., Swatling, S., et al. (1993). Comparison of prevention interventions for families with parental affective disorder. Journal of the American Academy of Child and Adolescent Psychiatry, 35(6), 774-782.

Beardslee, W. R., \& Wheelock, I. (1994). Children of parents with affective disorders. In W. M. Reynolds \& H. F. Johnston (Eds.), Handbook of depression in children and adolescents (pp. 463-479). New York: Plenum Press.

Boyle, M. H. P., \& Pickles, A. R. (1997). Influence of maternal depressive symptoms on ratings of childhood behavior. Journal of Abnormal Child Psychology, 25, 399-412.

Briggs-Gowan, M. J., Horwitz, S. M., Schwab-Stone, M. E., Leventhal, J. M., \& Leaf, P. J. (2000). Mental health in pediatric settings: Distribution of disorders and factors related to service use. Journal of the American Academy of Child and Adolescent Psychiatry, 39(7), 841-849.

Brugha, T. S., \& Cragg, D. (1990). The list of life threatening experiences: The reliability and validity of the Brief Life Events Questionnaire. ACTA Psychiatrica Scandinavica, 82, 77-81.

Burns, B. J., Costello, E. J., Erkanli, A., Tweed, D. L., Farmer, E. M. Z., \& Angold, A. (1997). Insurance coverage and mental health service use by adolescents with serious emotional disturbance. Journal of Child and Family Studies, 6(1), 89111.

Calsyn, R. J. (1993). Predicting perceived service need, service awareness, and service utilization. Journal of Gerontological Social Work, 21(1/2), 59-76.

Canino, G., Shrout, P. E., Alegria, M., Rubio-Stipec, M., Chavez, L. M., Ribera, J. C., et al. (2002). Methodological challenges in assessing children's mental health services utilization. Mental Health Services Research, 4(2), 97-108.

Cauce, A. M., Domenech-Rodriguez, M., Paradise, M., Cochran, B. N., Shea, J. M., Srebnik, D., et al. (2002). Cultural and contextual influences in mental health help-seeking: A focus on ethnic minority youth. Journal of Consulting and Clinical Psychology, 70(1), 44-55.

Cleveland, W. (1993). Visualizing data. Summit, NJ: Hobart Press.

Cohen, P., \& Hesselbart, C. S. (1993). Demographic factors in the use of children's mental health services. American Journal of Public Health, 83(1), 49-52.

Cornelius, J. R., Pringle, J., Jernigan, J., Kirisci, L., \& Clark, D. B. (2001). Correlates of mental health service utilization and unmet need among a sample of male adolescents. Addictive Behaviors, 26(1), 11-19.

Costello, E. J., Angold, A., Burns, B. J., Stangl, D. K., Tweed, D. L., Erkanil, A., et al. (1996). The Great Smoky Mountains Study of Youth: Goals, design, methods, and the prevalence of DSM-III-R disorders. Archives of General Psychiatry, 53, 1129-1136.

Costello, E. J., Burns, B. J., Angold, A., \& Leaf, P. J. (1993). How can epidemiology improve mental health services for children? Journal of the American Academy of Child and Adolescent Psychiatry, 32(6), 1106-1113.

Cuffe, S. P., Waller, J. L., Addy, C. L., McKeown, R. E., Jackson, K. L., Moloo, J., et al. (2001). A longitudinal study of adolescent mental health service use. Journal of Behavioral Health Services and Research, 28(1), 1-11.

DelBello, M. P., \& Geller, B. (2001). Review of studies of child and adolescent offspring of bipolar parents. Bipolar Disorders, 3(6), 325-334.

Farmer, E. M. Z., Stangl, D., Burns, B. J., Costello, E. J., \& Angold, A. (1999). Use, persistence, and intensity: Patterns of care for children's mental health across one year. Community Mental Health Journal, 35(1), 31-46.

Fergusson, D. M., \& Lynskey, M. T. (1993). The effects of maternal depression on child conduct disorder and attention deficit 
behaviours. Social Psychiatry and Psychiatric Epidemiology, $28,116-123$.

Friendly, M. (2001). Visualizing categorical data. Cary, NC: SAS Publishing.

Gibaud-Wallston, J., \& Wandersman, A. (1978). Development and utility of the Parenting Sense of Competence Scale. Paper presented at the meeting of the American Psychological Association, Toronto.

Goldberg, R. W., Seybolt, D. C., \& Lehman, A. (2002). Reliable self-report of health service use by individuals with serious mental illness. Psychiatric Services, 53(7), 879-881.

Goodman, S. H., \& Brumley, E. H. (1990). Schizophrenic and depressed mothers: Relational deficits in parenting. Developmental Psychology, 26(1), 31-39.

Hedeker, D. R., \& Gibbons, R. D. (1996). MIXOR—a computer program for mixed-effects ordinal regression analysis. Computer Methods and Programs in Biomedicine, 49(2), 157-176.

Hosmer, D. W., \& Lemeshow, S. (2000). Applied logistic regression (2nd ed.). New York: Wiley Interscience.

Kataoka, S. H., Zhang, L., \& Wells, K. B. (2002). Unmet need for mental health care among US children: Variation by ethnicity and insurance status. American Journal of Psychiatry, 159, $1548-1555$.

Kruse, G. R., Rohland, B. M., \& Wu, X. Y. (2002). Factors associated with missed first appointments at a psychiatric clinic. Psychiatric Services, 53(9), 1173-1176.

Lapalme, M., Hodgins, S., \& LaRoche, C. (1997). Children of parents with bipolar disorder: A metaanalysis of risk for mental disorders. Canadian Journal of Psychiatry, 42, 623-631.

Larsson, B., Knutsson-Medin, L., Sundelin, C., \& Trost von Werder, A. C. (2000). Social competence and emotional/behavioural problems in children of psychiatric inpatients. European Child and Adolescent Psychiatry, 9, 122-128.

Lavigne, J. V., Arend, R., Rosenbaum, D., Binns, H. J., Christoffel, K. K., Burns, A., et al. (1998). Mental health service use among young children receiving pediatric primary care. Journal of the American Academy of Child and Adolescent Psychiatry, 37(11), 1175-1183.

Levkovitz, V., Fennig, S., Horesh, N., Barak, V., \& Treves, I. (2000). Perception of ill spouse and dyadic relationship in couples with affective disorder and those without. Journal of Affective Disorders, 58(3), 237-240.

Lieb, R., Isensee, B., Hofler, M., Pfister, H., \& Wittchen, H. (2002). Parental major depression and the risk of depression and other mental disorders in offspring: A prospectivelongitudinal community study. Archives of General Psychiatry, 59(4), 365-374.

Mandell, D. S., Boothroyd, R. A., \& Stiles, P. G. (2003). Children's use of mental health services in different Medicaid insurance plans. Journal of Behavioral Health Services \& Research, 30(2), 228-237.

Mcmiller, W. P., \& Weisz, J. R. (1996). Help-seeking preceding mental health clinic intake among African-American, Latino, and Caucasian Youths. Journal of the American Academy of Child and Adolescent Psychiatry, 35, 1086-1094.

Miller, L. J. (1997). Sexuality, reproduction, and family planning in women with schizophrenia. Schizophrenia Bulletin, 23, 623635

Mowbray, C. T., Jordan, L. C., Kewalramani, A., Luke, D. A., Ribisl, K. M., Herman, S. E., et al. (1999). Analysis of postdischarge change in a dual diagnosis population. Health and Social Work, 24(2), 91-101.

Mowbray, C. T., Oyserman, D., Bybee, D., \& MacFarlane, P. (2003). Parenting of mothers with a serious mental illness: Differential effects of diagnosis, clinical history and other mental health variables. Social Work Research, 26(4), 225240 .

Mowbray, C. T., Schwartz, S., Bybee, D., Spang, J., Rueda-Riedle, A., \& Oyserman, D. (2000). Mothers with mental illness:
Stressors and resources for parenting and living. Families \& Society, 81, 118-129.

Nomura, Y., Wickramaratne, P. J., Warner, V., Mufson, L., \& Weissman, M. M. (2002). Family discord, parental depression, and psychopathology in offspring: Ten-year follow-up. Journal of the American Academy of Child and Adolescent Psychiatry, 41, 402-409.

Oyserman, D., Mowbray, C. T., Allen-Meares, P., \& Firminger, K. B. (2000). Parenting among mothers with a serious mental illness. American Journal of Orthopsychiatry, 70(3), 296315.

Pumariega, A. J., Glover, S., Holzer, C. E., \& Nguyen, H. (1998). Utilization of mental health services in a tri-ethnic sample of adolescents. Community Mental Health Journal, 34(2), 145156.

Raudenbush, S. W., \& Bryk, A. S. (2002). Hierarchical linear models: Application and data analysis methods (2nd ed.). Thousand Oaks, CA: Sage.

Ringel, J. S., \& Sturm, R. (2001). National estimates of mental health utilization and expenditures for children in 1998. Journal of Behavioral Health Services and Research, 28(3), 319333.

Ritsher, J. E. B., Coursey, R. D., \& Farrell, E. W. (1997). A survey on issues in the lives of women with severe mental illness. Psychiatric Services, 48, 1273-1282.

Robins, L. N., Helzer, J. E., Croughan, J., \& Ratcliff, K. S. (1981). National Institute of Mental Health Diagnostic Interview Schedule: Its history, characteristics, and validity. Archives of General Psychiatry, 38(4), 381-389.

Rosenheck, R., \& Lam, J. A. (1997). Individual and communitylevel variation in intensity and diversity of service utilization by homeless persons with serious mental illness. Journal of Nervous \& Mental Disease, 185(10), 633-638.

Rosenheck, R., \& Lam, J. A. (1994). Client Access Evaluation Form. West Haven, CT: Northeast Program Evaluation Center.

Sands, R. G. (1995). The parenting experience of low-income single women with serious mental disorders. Families in Society-The Journal of Contemporary Human Services, 76, $86-96$.

Saunders, S. M., Resnick, M. D., Hoberman, H. M., \& Blum, R. W. (1994). Formal help-seeking behavior of adolescents identifying themselves as having mental health problems. Journal of the American Academy of Child \& Adolescent Psychiatry, 33(5), 718-728.

Skinner, H. A. (1982). The Drug Abuse Screening Test. Addictive Behaviors, 7(4), 363-371.

Stein, J. A., Andersen, R. M., Koegel, P., \& Gelberg, L. (2002). Predicting health services utilization among homeless adults: A prospective analysis. Journal of Health Care for the Poor \& Underserved, 11(2), 212-230.

Striley, C. W., Stiffman, A. R., \& Spitznagel, E. L. (2003). Functioning mediates between symptoms and provider assessment. Mental Health Services Research, 5(3), 155-171.

Tamarit, L. M., \& Lau, A. Y. H. (1999). Children's needs when their mothers are admitted to psychiatric units. Psychiatric Bulletin, 23(4), 214-217.

Weissman, M. M., Warner, V., Wickramaratne, P., Moreau, D., \& Olfson, M. (1997). Offspring of depressed parents: 10 years later. Archives of General Psychiatry, 54(10), 932-940.

Wu, P., Hoven, C. W., Bird, H. R., Moore, R. E., Cohen, P., Alegria, M., et al. (1999). Depressive and disruptive disorders and mental health service utilization in children and adolescents. Journal of the American Academy of Child and Adolescent Psychiatry, 38(9), 1081-1090.

Wu, P., Hoven, C. W., Cohen, P., Liu, X., Moore, R. E., Tiet, Q., et al. (2001). Factors associated with use of mental health services for depression by children and adolescents. Psychiatric Services, 52(2), 189-195. 
Youngstrom, E., Izard, C., \& Ackerman, B. (1999). Dysphoriarelated bias in maternal ratings of children. Journal of Consulting and Clinical Psychology, 67(6), 905916.

Zahner, G. E. P., \& Daskalakis, C. (1997). Factors associated with mental health, general health, and school-based service use for child psychopathology. American Journal of Public Health, 87(9), 1440-1448.

Zemencuk, J., Rogosch, F. A., \& Mowbray, C. T. (1995). The seriously mentally ill woman in the role of parent: Characteristics, parenting sensitivity, and needs. Psychosocial Rehabilitation Journal, 18, 77-92. 